Supplement of Geosci. Model Dev., 11, 4085-4102, 2018

https://doi.org/10.5194/gmd-11-4085-2018-supplement

(C) Author(s) 2018. This work is distributed under

the Creative Commons Attribution 4.0 License.

(c) (1)

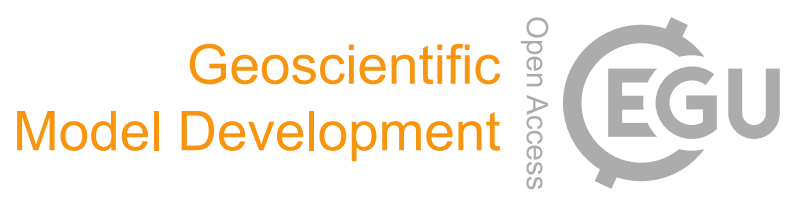

Supplement of

\title{
Development and evaluation of a variably saturated flow model in the global E3SM Land Model (ELM) version 1.0
}

Gautam Bisht et al.

Correspondence to: Gautam Bisht (gbisht@lbl.gov)

The copyright of individual parts of the supplement might differ from the CC BY 4.0 License. 


\section{Sensitivity of simulated water table depth to spatial and temporal discretization}

To investigate the sensitivity of water table depth (WTD) simulated by VSFM, we performed the following two addition 10-years simulations:

- SIM_HALF_DT: All configurations were the same as those used in the global simulation with optimal $f_{d}$ except maximum allowable VSFM timestep was set to 15 $\min$

- SIM_HALF_DT_AND_HALF_DZ: All configurations were the same as those used in the global simulation with optimal $f_{d}$ except maximum allowable VSFM timestep was set to 15 min and spatial resolution of ELM was doubled by increasing the number of soil layers to 118 and decreasing the soil thickness for each layer appropriately to keep the total soil column depth fixed at $150 \mathrm{~m}$.

The results are encouraging: the global mean difference in the simulated annual WTD for the 10th year between SIM_OPT and SIM_HALF_DT at $25^{\text {th }}, 50^{\text {th }}$, and $75^{\text {th }}$ percentiles were extremely small (0.001, 0.002 and $0.005 \mathrm{~m}$, respectively). Small difference between SIM_OPT and SIM_HALF_DT_AND_HALF_DZ at $25^{\text {th }}, 50^{\text {th }}$, and $75^{\text {th }}$ percentiles were also found $(0.091,0.488,0.945[\mathrm{~m}]$, respectively). These results show that simulated WTD is insensitive to VSFM sub timestep, and has small sensitivity to vertical spatial resolution.

\section{Computational cost of VSFM}

In order to evaluate the computational costs of VSFM as compared to the default model, two 5-year long ELM simulations were performed with VSFM and ZD. ELM simulations were performed using 96, 192, 384, 768, and 1536 MPI tasks cores on the Edison supercomputer at the National Energy Research Scientific Computing Center. The total run time decreases with increasing number of cores for both physics formulations (Figure $\mathbf{S}$ 1a). The VSFM model is more expensive than the default model at all core counts (Figure $\mathbf{S}$ 1b). At low core count VSFM formulation is significantly more expensive that the default model (e.g. VSFM is $3.1 \mathrm{x}$ more expensive than ZD at 96 cores). The cost of VSFM relative to ZD decreases rapidly as number of cores increases and VSFM is only 1.3 times more expensive than the default ELMv1 model at 1536 cores. We note that the relative 
computational cost of the land model in a fully coupled global model simulation is generally very low. Dennis et al. (2012) reported computational cost of the land model to be less than $1 \%$ in ultra-high-resolution CESM simulations.

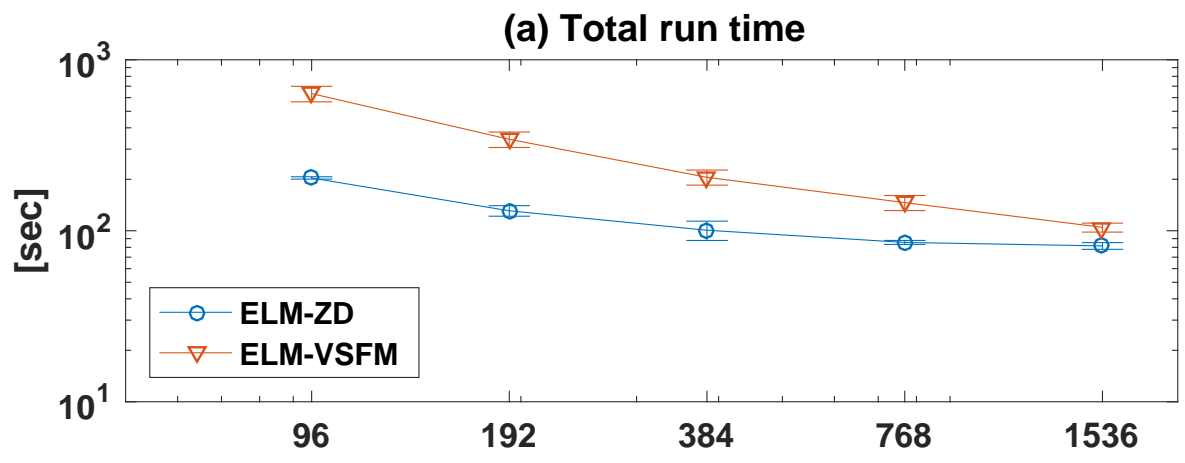

(b) Relative computational cost



Figure $S 1$ (a) Total run time for a 5-year ELM simulation with ZD and VSFM formulation; (b) Relative computation cost of VSFM as compared to ZD.

\section{References}

Dennis, J. M., Vertenstein, M., Worley, P. H., Mirin, A. A., Craig, A. P., Jacob, R., and Mickelson, S.: Computational performance of ultra-high-resolution capability in the Community Earth System Model, The International Journal of High Performance Computing Applications, 26, 5-16, 2012. 